\title{
Design of green concrete made of plant-derived aggregates and a pumice-lime binder
}

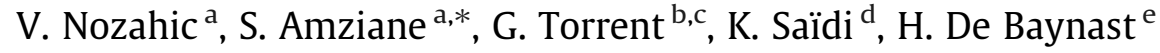 \\ a Clermont Université, Polytech'Clermont-Ferrand, EA 3867, LaMI, BP 10448, F-63000 Clermont-Ferrand, France \\ ${ }^{\mathrm{b}}$ Clermont Université, Université Blaise Pascal, LMV, BP 10448, F-63000 Clermont-Ferrand, France \\ ${ }^{\mathrm{C}}$ CNRS, UMR 6524, LMV, F-63038 Clermont-Ferrand, France \\ ${ }^{\mathrm{d}}$ Clermont Université, ENSACF, F-63000 Clermont-Ferrand, France \\ e Clermont Université, Polytech'Clermont-Ferrand, EA 3866, LGCB, BP 10448, F-63000 Clermont-Ferrand, France
}

The use of particles from agricultural lignocellulosic resources in concrete gives it desirable environmen-tal and multiphysics qualities. In this study, parallels are drawn between particles derived from hemp and sunflower stems, in terms of their morphological and physical properties. A pumice-lime binder is proposed as an alternative to the traditional cement or lime based solutions for both environmentally friendly and mechanical qualities. Compaction is applied during casting and its effects on mechanical properties are analysed. A principal finding of this study is that the hemp and sunflower materials show large similarities in terms of morphology and mechanical performance of the resulting concrete. The pumice-lime binder provides desirable properties even with raw pumice sand, which represent $90 \%$ of the binder mass proportion. Compaction level during casting induces an orthotropy, even with low plant content, and increases the compressive strength. A simple analytical model using Powers' equation is proposed to predict plant concrete compressive strength with low plant quantities.

\section{Introduction}

For construction, the use of many different fibres, woods and by-products issued from plants has already been scientifically studied, mostly near their natural habitats and processing locations. The main goal of these additions was first to reinforce concrete in terms of tensile strength, ductility and post cracking behaviour. The addition of fibrous matters from plant or animal origin to building materials has been done intuitively since Antiquity. However, scientific study of Fibre Reinforced Concretes (FRC) made with mineral or synthetic fibres began in the early 20th [1]. Recently, organic fibres were considered to substitute mineral or synthetic ones. They come from several resources, such as hard and soft wood [2,3], hemp [4], coconut, sisal [5-7], date palm [8], bamboo [9] or bagasse [10,11]. Brazil, which disposes of a wide range of plant resources, produces much research in this field $[12,13]$.

In recent years, lignocellulosic by-product use in concrete addresses other issues. The woody part of the stem is now being considered with increasing interest, as well as epidermis fibres. This is

\footnotetext{
* Corresponding author.

E-mail addresses: vincent.nozahic@polytech.univ-bpclermont.fr (V. Nozahic) sofiane.amziane@univ-bpclermont.fr (S. Amziane).
}

linked to the desire of material and building designers to use local materials, which are by-products or wastes, as much as possible [14]. Few cellulosic or lignocellulosic plant aggregates have been studied to see how they meet these criteria. This is the case with residues from the wood industry. Between $5 \%$ and $10 \%$ of sawdust, chip or dust wastes in mass are generated during transformation processes $[15,16]$. Polymer based composites and textile industry needs for organic natural fibres could also be an important plant by-product generator. In France, the resources used are mainly hemp and flax plants, which are cultivated for their fibrous stem. They are mostly used for thermal energy production and animal mulching [17]. Flax shive is one of these woody lignocellulosic by-products. It represents $70 \%$ of flax stem volume and could be used to design building materials $[18,19]$. However, French and Belgian hemp industries have been better structured for building applications than the flax industry. Lime and Hemp Concrete (LHC) has been the subject of research for more than 10 years, especially in these two countries. Due to the low density and high porosity of the hemp hurd, the combination of hemp and a cementitious binder creates a building material with properties that differ from those of conventional concrete. It has a lower density, lower thermal conductivity and higher permeability [20-22]. However, its strength is very low compared to usual building materials. Currently, the compressive strength of this material is lower than $2 \mathrm{MPa}[23,24]$. Use as a load bearing material is then not possible. 
LHC is mainly integrated in combination with a load bearing wooden framework. It is also useful in renovation as a thermal and acoustic insulation layer upon a traditional wall. Depending on its composition, it can be used in floors and as roof filling [21]. LHC axial compressive strength ranges from 0.2 to $0.9 \mathrm{MPa}$, depending on the mix design and the binder used [21,23-25].

LHC set up can be done by manually pouring a framework or by a projection process directly on the wall [24]. These processes do not achieve a high compactness or process repeatability. Industrially compacted LHC bricks or hollow blocks are designed to compensate for these problems. However, little scientific data are available on the effect of compactness of mechanical or thermal properties [21,26,27]

Previous work $[25,26]$ has shown that fresh material compaction can significantly increase the compressive strength of hemp concrete by reducing void volume within the material. Such a process increases the mechanical strength of the produced material, while using lower binder contents. Also, it particularly magnifies the strain capacity before collapse. Although it does induce a decrease of the entrapped air volume that contributes to reducing the hardened material thermal performances.

Concretes made from plant aggregates are commonly formulated with cementitious or lime binders. Binder design requires high energy consumption which limits their interest for ecological building materials. Their compatibility with polysaccharide carbohydrate rich plants seems to be limited as delay or even lack of setting can occur. Literature explains polysaccharide migration in the cement matrix interacts with binder hydration reactions retarding hydrate formation $[28,29]$. Another mechanism is detailed by Sedan et al. [30] who relates $\mathrm{Ca}^{2+}$ fixation on hemp fibres in alkaline media. The author underlines the major role of surface covering pectins in this process. Pectins are acidic polysaccharide polymers able to fix divalent metal cations in their molecular structure $[31,32]$. This phenomenon is enhanced by the alkaline $\mathrm{pH}$ created by cementitious or lime binders. $\mathrm{Ca}^{2+}$ ion lack in the matrix surrounding plant particles could consequently explain setting problems as hydrate formation will be disrupted.

The use of more acid minerals as pumice sand or natural pozzolan could then be an interesting track to elaborate plant specific binders. Pumice has been widely studied to make lightweight concrete [33] or insulating low-density blocks [34], as well as cement additive to increase concrete durability and alkali resistance properties [35]. When mixed with lime and water, a fine-grained pumice or pozzolan powder create a lightweight, smooth and plasterlike binder. This kind of cement was used as far back as Roman times.

A pozzolanic binder based on iron black furnace slag using gypsum and lime as activators has already been successfully mixed with plant fibres [36]. However, few studies exist on concrete designed with a pozzolanic binder mixed with light plant aggregates. In light of these elements, an alternative study was done, the first objective of which was to give value to raw materials and agricultural by-products from central France. The binders elaborated in this work were based on pumice sand activated with hydrated calcic lime (calcium hydroxide, CL90, EN459-1). The choice of pumice was imposed by the nearness of the central massive region, which is one of the largest volcanic mountains in Europe. This provides us with interesting raw material without significant transport and with low-energy processes (easy extraction from quarries and no heating). Local volcanic sources have already been used and characterised by Pichon during his PhD thesis [37]. Sunflower stems were chosen as the plant aggregate. This agricultural by-product seems to be closed to hemp from a morphological point of view. Also sunflower stalks can be easily collected in big quantities and stored with available agricultural equipment. Tests were also performed on hemp hurd taken as a reference aggregate.

\section{Materials and methods}

\subsection{Raw materials}

\subsubsection{Plant aggregates}

Two plant aggregates were used for this work and are shown in Fig. 1. The first one was a commercial hemp hurd resulting from an industrial process [17] and is hauled from hemp stem. Hemp hurd aggregate was taken as reference as it is already used in association with a lime based binder. Sunflower stem was selected as an alternative lignocellulosic by-product for its apparent similarities with hemp hurd. Sunflower aggregates were obtained from raw stems directly ground in a laboratory helix grinder. Particles obtained were washed with clear water until the elimination of residual soil before $60{ }^{\circ} \mathrm{C}$ drying for $48 \mathrm{~h}$. Dry sieving between 1 and $5 \mathrm{~mm}$ was used for experiments.

\subsubsection{Mineral resources}

Mineral resource chemical and physical characteristics are detailed in Table 1. Pumice sand chemical analysis is provided from the work of Pichon [37]. Bulk densities were determined from the average of six specimens for each resource.

Hydrated calcic lime (EN 459-1 standard) has been chosen instead of hydraulic lime for its ability to generate only pozzolanic and carbonation reactions. Furthermore, some authors report a better durability of hydrated lime mortars [38].

Trachytic pumice sand was directly obtained from the raw material drawn from the quarries and simply sifted. Its grading curve (See Fig. 2) indicates that this is a coarse sand containing $18 \%$ by mass of elements less than $32 \mu \mathrm{m}$ and $90 \%$ less than $2 \mathrm{~mm}$.

\subsection{Concrete design}

Three different concretes were designed. Mix proportioning for each mixture is detailed in Table 2. For mixes including lignocellulosic aggregates, Binder/Aggregate mass ratio (B/A) was fixed to 18 . Three $40 \times 40 \times 160 \mathrm{~mm}$ specimens were cast each time under two different loads ( 2 and $5 \mathrm{MPa}$ ). The mixing process was identical for each batch and has been detailed in previous study [26]. The compaction device is shown in Fig. 3. It consists of a mould (1) reinforced by a clamping system (2) and (3), a removable bottom (4) and a jack (5) moving down during loading. The initial apparent
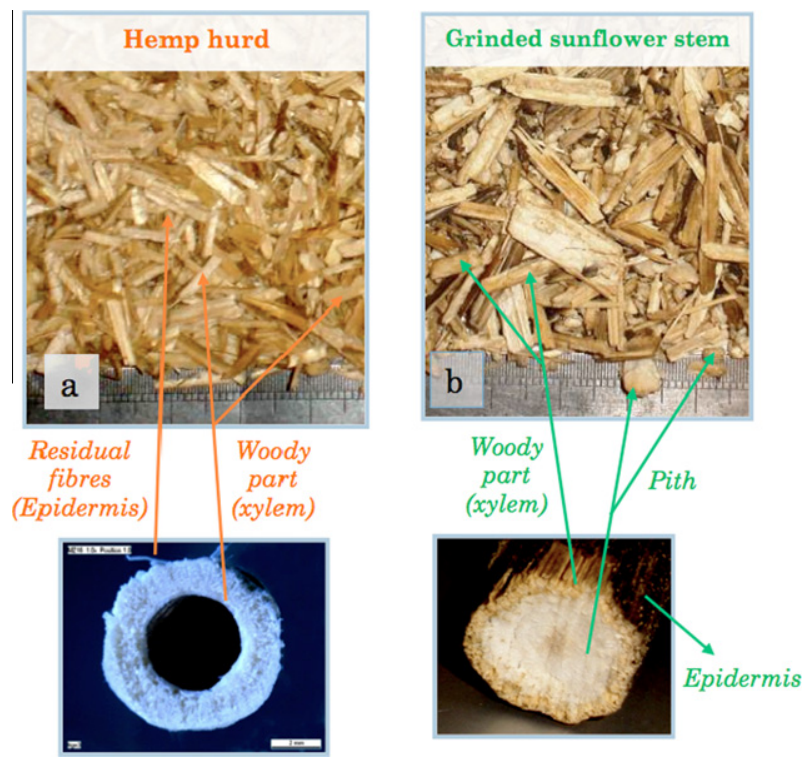

Fig. 1. Macroscopic observation of hemp stem (a) and sunflower stem (b) aggregates. 
Table 1

Chemical composition and densities of binder raw materials.

\begin{tabular}{|c|c|c|c|c|c|c|c|c|c|}
\hline & $\begin{array}{l}\mathrm{CaO} \\
(\%)\end{array}$ & $\begin{array}{l}\mathrm{SiO}_{2} \\
(\%)\end{array}$ & $\begin{array}{l}\mathrm{Al}_{2} \mathrm{O}_{3} \\
(\%)\end{array}$ & $\begin{array}{l}\mathrm{Na}_{2} \mathrm{O} \\
(\%)\end{array}$ & $\begin{array}{l}\mathrm{K}_{2} \mathrm{O} \\
(\%)\end{array}$ & $\begin{array}{l}\mathrm{Fe}_{2} \mathrm{O}_{3} \\
(\%)\end{array}$ & $\begin{array}{l}\text { Bulk density } \\
\left(\mathrm{kg} \mathrm{m}^{-3}\right)\end{array}$ & $\begin{array}{l}\text { Specific density } \\
\left(\mathrm{kg} \mathrm{m}^{-3}\right)\end{array}$ & $\begin{array}{l}\text { Saturated solution } \\
(\mathrm{pH})\end{array}$ \\
\hline Pumice sand [37] & 1.1 & 62.2 & 17.3 & 5.9 & 6.3 & 2.7 & 1050 & 2115 & 7.5 \\
\hline $\begin{array}{l}\text { Pumice sand soluble part in hydrofluoric } \\
\text { acid [37] }\end{array}$ & - & 52.6 & 17.5 & 6 & 6.3 & - & - & - & - \\
\hline Lime CL90 (EN 459-1) & $>94$ & - & - & - & - & - & 450 & 2525 & 12.6 \\
\hline
\end{tabular}

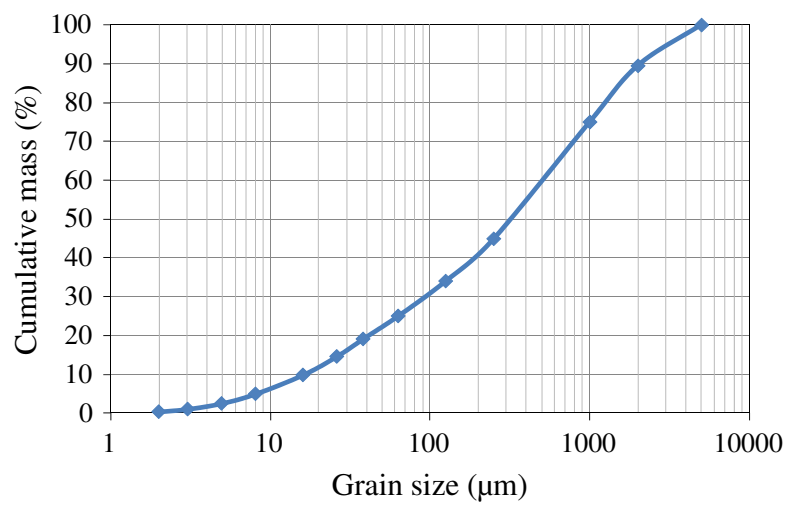

Fig. 2. Pumice sand granulometric curve.

volume of the mixture poured in the mould is divided by a compaction factor up to 1.5 during the process. It is important to notice the increase of this factor ( $\approx 3$ typically) when mix proportioning includes more plant aggregates $(\mathrm{B} / \mathrm{A} \approx 2$ for Lime and Hemp Concrete wall mixture). After casting, specimens were left in the moulds for $48 \mathrm{~h}$ before removal and storage in a $20^{\circ} \mathrm{C}$ and humidity saturated air-conditioned vessel until testing. Saturated atmosphere was chosen in order to prevent hydrated lime carbonation effect. Carbonation control tests were done on fresh fractures by spraying a coloured indicator, phenolphthalein.

\subsection{Experimental methods}

\subsubsection{Plant aggregate bulk density and water absorption}

Lignocellulosic aggregates were heated at $60^{\circ} \mathrm{C}$ for $48 \mathrm{~h}$ before experimentation. Water absorption mass was measured by sequential weights after $1,2,5,10,30 \mathrm{~min}$ and $24 \mathrm{~h}$ of immersion. With this method, it is impossible to remove water creating bridges and bonds between particles. Bulk density was determined from the average of six specimens for each source.

\subsubsection{Plant aggregates image analysis}

To better visualise aggregate size distribution and morphology, an image quantitative analysis method was chosen. It is used in material research [39], but few studies have been done to characterise specifically plant particles for building applications [25]. Aggregates are beforehand coloured in methylene blue for better image contrast and particle colour homogenisation. After drying, they are carefully spread out on a $420 \times 297 \mathrm{~mm}$ sheet of paper (See Fig. 4a). The image treatment approach is driven in 4 steps. First, image is acquired with a numerical camera with 6 million pixels resolution. The second step consists in several treatments like correcting brightness heterogeneity. Image binarisation is then applied to the corrected picture. In a third operation, each object outline is detected on the binary image and each pixel coordinates are determined in the good unit after spatial calibration. With this information, image software calculates particle dimensional and morphological parameters for statistical data treatment.
The main advantage of this method compared to sieve grading is to achieve characterisation of complex particle morphology and heterogeneity. Nevertheless, statistical study is limited to small aggregate quantities and hemp hurd residual fibres cannot be detected. The morphological parameters kept for analysis are the following:

- Area: The area of the object, measured as the number of pixels in the polygon. If spatial measurements have been calibrated for the image, then the measurement will be in the units of that calibration.

- Major axis length: Size of the longest line that can be drawn in the object (See Fig. 4b).

- Minor axis length: Size of the longest line that can be drawn in the object on the major axis perpendicular direction.

- Equivalent diameter: The diameter of a circle having the same area as the object, it is computed as:

$$
\text { Equivalent diameter }=\sqrt{\frac{4 * \text { Area }}{\pi}}
$$

- Particle sphericity: Basically the ratio of the equivalent diameter to the object's major axis length. It ranges between 0 and 1. At 1 , the object is roughly circular. As the ratio decreases from 1 , the object becomes less circular.

Particle sphericity $=\frac{\text { Equivalent diameter }}{\text { Major axis length }}$

\subsubsection{SEM observations and EDX analysis}

Plant aggregate microstructure morphology and also plant concrete observations were realised by means of scanning electron microscopy (SEM). The microscope used for the study was a JEOL JSM-5910LV. Additional semi-quantitative chemical analysis by means of Energy Dispersive X-ray spectroscopy (EDX) was also performed on plant concrete matrix with a PGT Prism device.

\subsubsection{Compression tests}

Compression tests were performed on a hydraulic machine with a $50 \mathrm{kN}$ capacity. They were conducted on $40 \times 40 \times 40 \mathrm{~mm}$ cubes with a $5 \mathrm{~mm} / \mathrm{min}$ speed. Specimens were taken out of an air-conditioned room $24 \mathrm{~h}$ before testing. Two replications were done for each mix and at each testing time.

\section{Results and discussion}

\subsection{Plant aggregate characterisation}

\subsubsection{Morphological characterisation}

From a morphological point of view, the two aggregates possess a similar lignocellulosic part (See Fig. 1). This woody lignocellulosic core has a parallepipedic shape (length: 10-30 mm, width: 2$10 \mathrm{~mm}$ ) with a thickness in a 1-2 mm range. Ground sunflower stem also shows an important quantity of pith that represents almost $60 \%$ of the stem volume [40]. Cellulosic pith can be observed as round particles with a diameter from 1 to $6 \mathrm{~mm}$ in the grinding. 
Compositions in dry mass volume of each mixes components obtained from compacted specimens final dry density and mixing parameters detail.

\begin{tabular}{|c|c|c|c|c|c|c|}
\hline & & Pumice sand (\%) & Lime CL90\% & Vegetable (\%) & Water/Binder ratio & Compaction strain (MPa) \\
\hline $\mathrm{B}-5 \mathrm{MPa}$ & Pumice-lime binder & 90 & 10 & - & 0.25 & 5 \\
\hline $\mathrm{H}-2 \mathrm{MPa}$ & Hemp aggregate + binder & 84.7 & 10 & 5.3 & 0.3 & 2 \\
\hline $\mathrm{S}-2 \mathrm{MPa}$ & & & & & & 5 \\
\hline $\mathrm{H}-5 \mathrm{MPa}$ & Sunflower aggregate + binder & 84.7 & 10 & 5.3 & 0.3 & 2 \\
\hline $\mathrm{S}-5 \mathrm{MPa}$ & & & & & & 5 \\
\hline
\end{tabular}

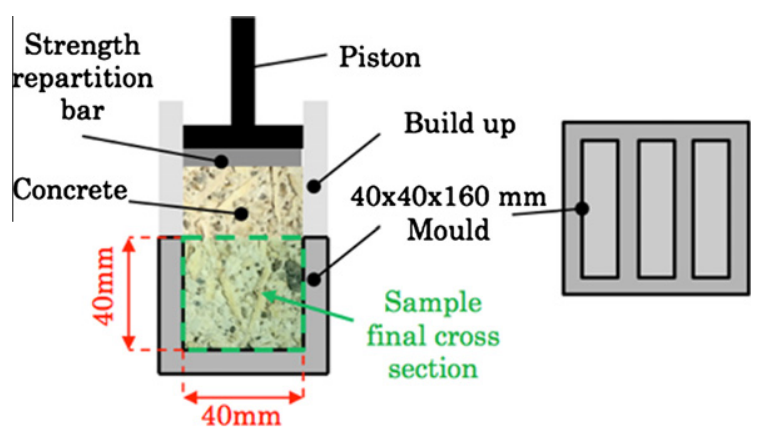

Fig. 3. Concrete mixture compaction process.

A very low bulk density because of their highly porous structure characterises these aggregates. Measurements give similar results for hemp hurd $\left(103 \pm 2 \mathrm{~kg} \mathrm{~m}^{-3}\right)$ and for ground sunflower stem aggregate (105 $\pm 2 \mathrm{~kg} \mathrm{~m}^{-3}$ ). In their study, Yin et al. [40] measured a $37 \pm 2.2 \mathrm{~kg} \mathrm{~m}^{-3}$ bulk density for sunflower pith.

For a more detailed observation of macroscopic morphological and size differences between commercial hemp hurd and sunflower stem aggregates, an image-processing method was used. For each specimen, $4 \mathrm{~g}$ were characterised. (See Fig. 5a) results show bigger extreme dimensions for sunflower aggregate than hemp. It is important to notice that an equivalent diameter can be a good medium between a major and minor axis. The average equivalent diameter of the samples is $5 \mathrm{~mm}$ for ground sunflower and $3.7 \mathrm{~mm}$ for hemp hurd. Particle sphericity factor statistical treatment makes it possible to see a normal distribution for each of the aggregates (See Fig. 5b). Hemp and sunflower aggregate sphericity average and standard deviation are respectively $0.58 \pm 0.15$ and $0.61 \pm 0.19$. The factor average is quite similar, but sunflower shows a bigger standard deviation. It is due to the presence of round pith particles and long wood needles, which increased extreme values in crushed sunflower.

SEM observations show for the two stems a close microscopic structuring due to a close histology (See Fig. 6). We first observe an epidermis or bark, constituted by fibres for hemp. A second layer of complex structure, called xylem, represents the woody part of the stem. It is lignin rich and made of different parts, notably the stem vascular vessels (See Fig. 7). Finally, the stem centre is filled with cellulosic pith with a honeycomb structure. Commercial hemp hurd is in fact only constituted of the woody part and of residual fibres. Diameter of the woody part pipes and pith cavities are respectively close to 20 and $100 \mu \mathrm{m}$. Pipe and cavity wall thickness are respectively close to $10 \mu \mathrm{m}$ and $2 \mu \mathrm{m}$.

\subsubsection{Absorption behaviour}

High porosity and internal structuring of the two aggregates are responsible for a high water absorption and retention capacity. Two distinct stages can be observed. A rapid weight increase is observed during the first minutes (See Fig. 8 - Stage 1). Absorption kinetic during first stage is very close between the two aggregates (See Table 3). After 5 min, 300\% percent higher wet mass compared to initial dry mass is measured for the two plants. A second absorption stage, slow and continuous, is visible after these five minutes. For commercial hemp hurd, second stage kinetic is 5 times lower than that of the sunflower aggregate (See Fig. 8 - Stage 2). This is due to sunflower aggregate pith particles of alveolar and closed structure [41]. Numerous physical characteristics of plant concrete, notably thermal and acoustic are greatly modified by water presence and content $[21,22]$. This essential characteristic also induces a competition between plant and binder water demand, which starts with concrete mixing. As sunflower stem aggregate behaviour is close to that of hemp during the first minutes, sunflower stem could benefit from the technical knowledge used on hemp for the mixing operation.

\subsubsection{Chemical analysis}

From the point of view of chemical composition, values from the literature shows interesting similarities between hemp and sunflower. Results from several studies are summarised in Table 4 [30,41-43] Hemp and sunflower woody parts have respectively cellulose content close to $50 \%$ and $40 \%$ in mass. This percentage reaches $47.4 \%$ for sunflower stem pith [40]. Lignin contents seem to be higher for hemp hurd (28\%) than for sunflower stem woody (a)

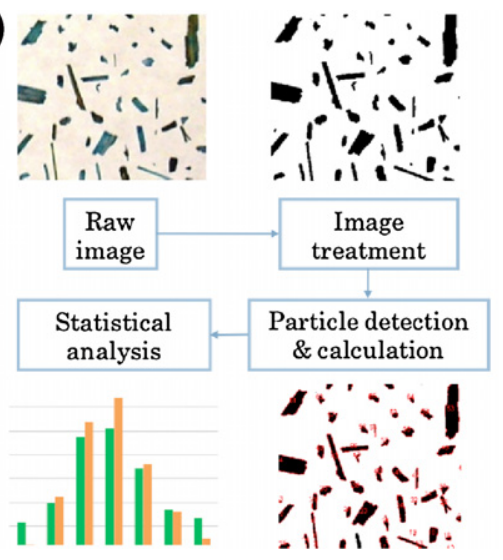

(b)

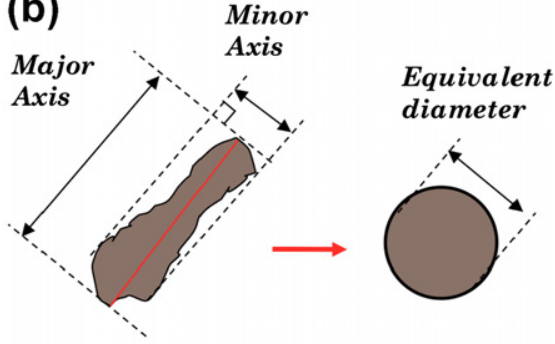

Fig. 4. Vegetable aggregate image treatment procedure (a) and particle size parameters determined with ImageTool software calculation (b). 

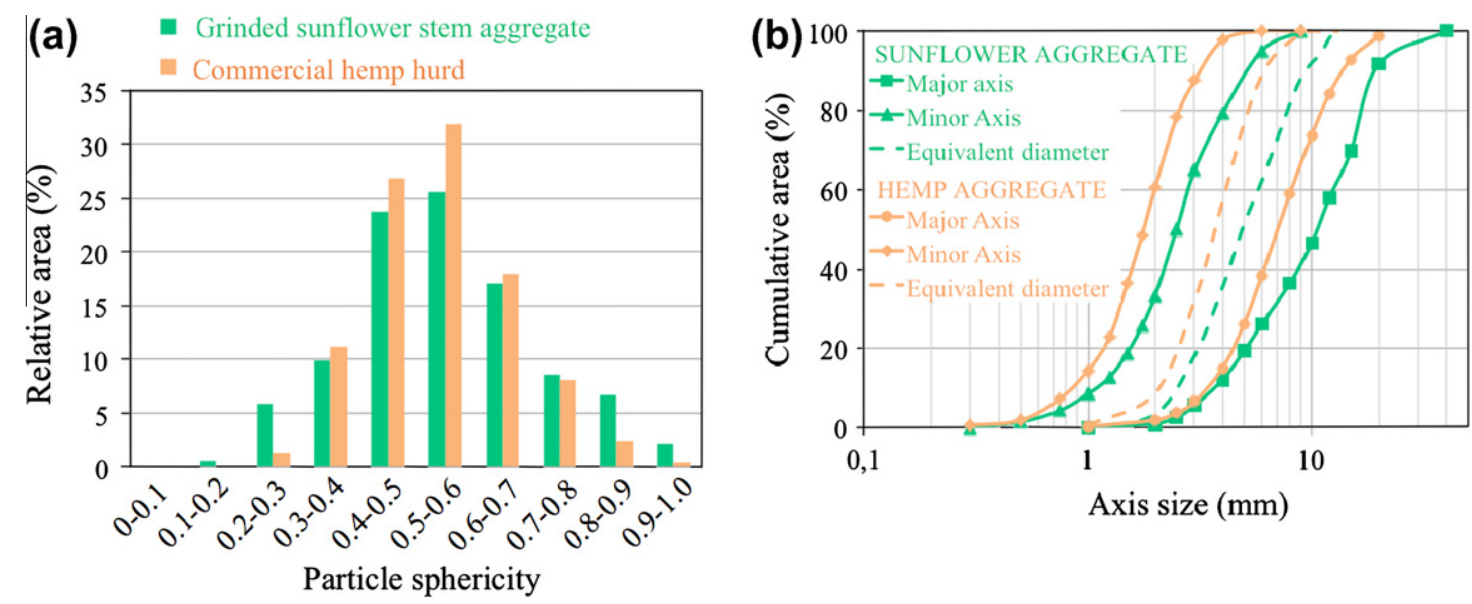

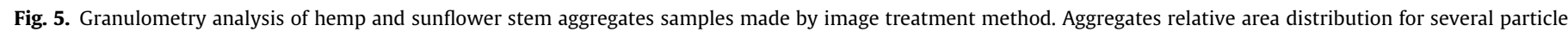
sphericity classes (a) and cumulative area distribution of previously defined particle size parameters (b).
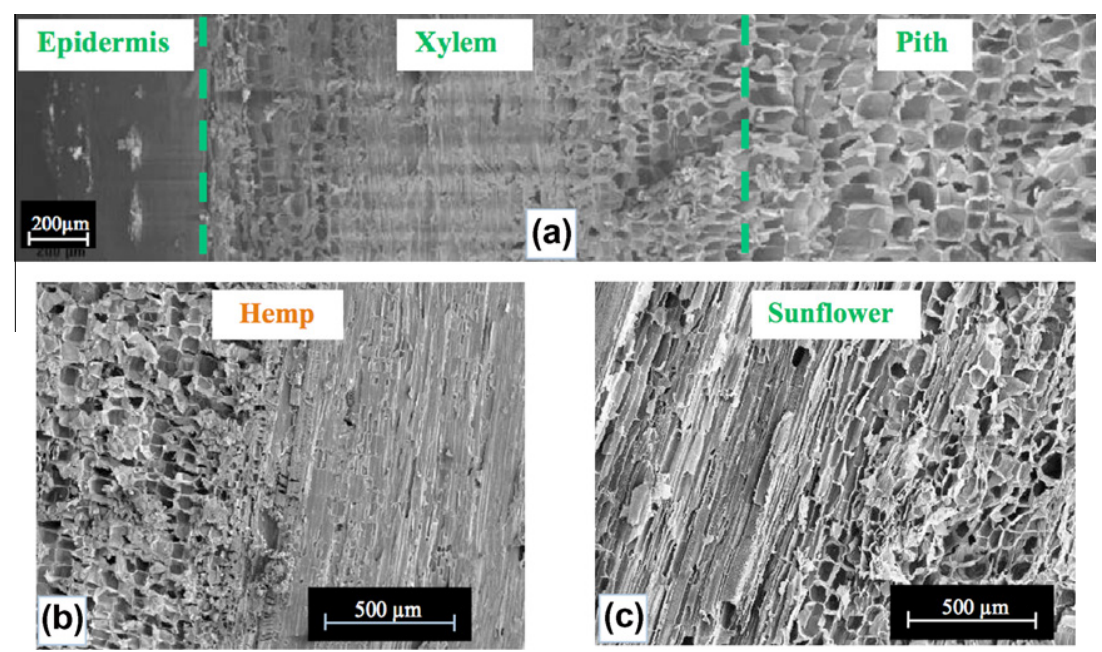

Fig. 6. Sunflower stem longitudinal section SEM analysis (a), comparative observation of hemp (b), and sunflower (c) stem xylem longitudinal section.
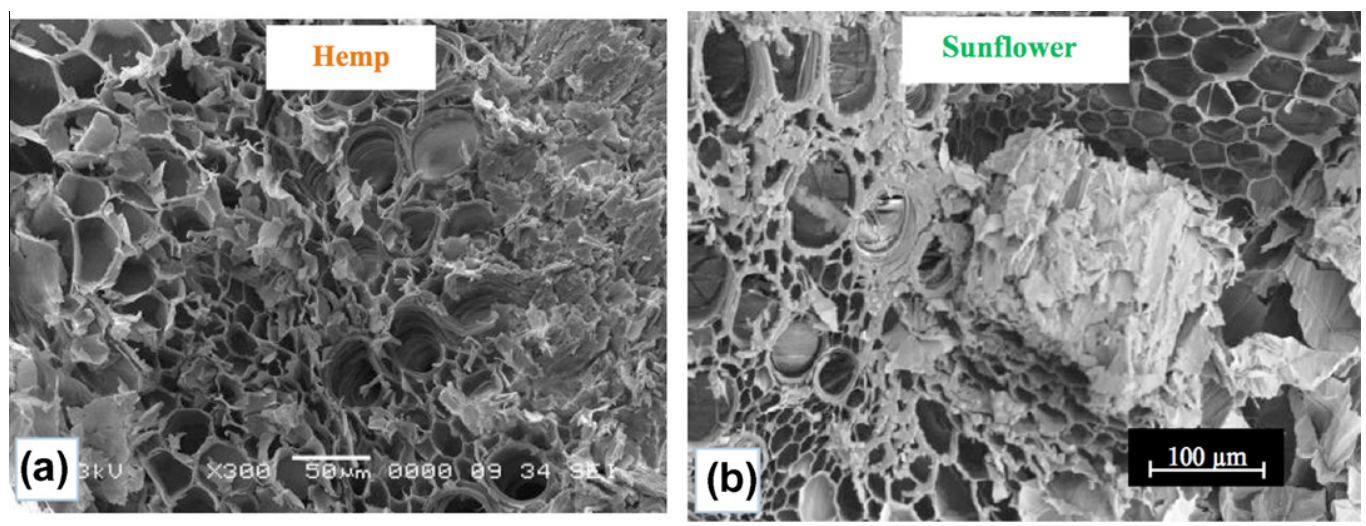

Fig. 7. Comparative observation of hemp (b) and sunflower (c) stem xylem cross section.

part (18.3\%), but this result greatly changes with plant evolution and age. As expected, sunflower cellulosic pith is a lignin weak product (3.5\%). An interesting point is the pectin content which is equal for hemp hurd, sunflower stem woody part and sunflower stem pith (6\%). This value is really low compared to hemp fibres ( 20\%). These comparisons suffer of uncertainties because methods used to obtain these values can change, as well as the harvest age and the species. A correct comparison should take into account these parameters for a global study of the two stems. 


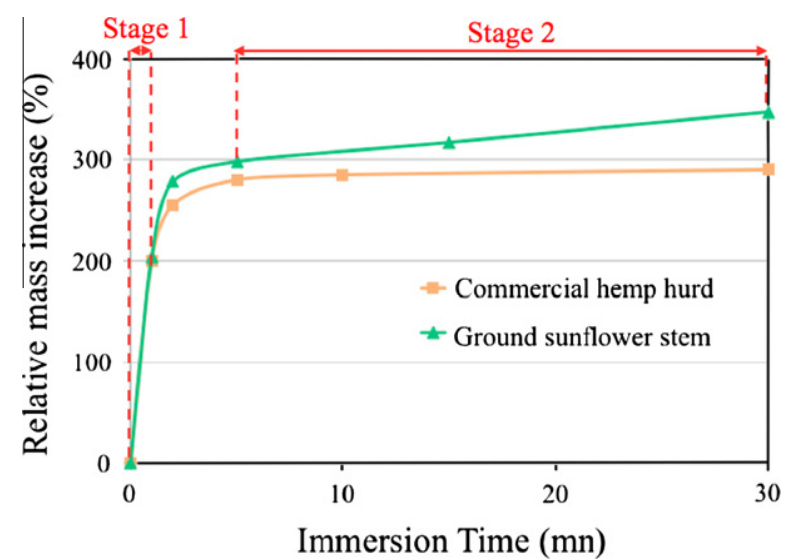

Fig. 8. Mass relative water absorption of commercial hemp hurd and ground sunflower stem aggregate.

Table 3

Lignocellulosic aggregates physical characteristics.

\begin{tabular}{cllll}
\hline Aggregate & $\begin{array}{l}\text { Dry bulk } \\
\text { density } \\
\left(\mathrm{kg} \mathrm{m}^{-3}\right)\end{array}$ & $\begin{array}{l}\text { Absorption } \\
\text { kinetic }(\text { Phase } \\
1)\left(\% \mathrm{~min}^{-1}\right)\end{array}$ & $\begin{array}{l}\text { Absorption } \\
\text { kinetic }(\text { Phase } \\
\text { 2) }\left(\% \mathrm{~min}^{-1}\right)\end{array}$ & $\begin{array}{l}\text { Absorption } \\
\text { rate after } \\
24 \mathrm{~h} \mathrm{( \% )}\end{array}$ \\
\hline $\begin{array}{c}\text { Hemp } \\
\text { hurd } \\
\begin{array}{c}\text { Sunflower } \\
\text { stem }\end{array}\end{array}$ & 103 & 185 & 0.4 & 406 \\
\hline
\end{tabular}

\subsection{Mechanical properties}

\subsubsection{Binder mechanical testing}

A preliminary study was done with different lime content (5\%, $10 \%, 20 \%$ and $30 \%$ in weight) with the purpose to find the best compromise between lime content and compressive strength. As our aim was to make a binder with as low energy consumption as possible, we tried to minimise lime content. Results show interesting properties for a mix designed with $90 \%$ of pumice sand and $10 \%$ of CL90 lime with 8.3 MPa compressive strength at 28 days for a $5 \mathrm{MPa}$ compaction (Fig. 9). At the same time, the use of $20 \%$ of lime instead of 10 does not greatly improve this result. It was then decided to use this binder for the rest of the study.

Analysis of binder's compressive strength from 7 to 60 days clearly underlines a logarithmic increase (Fig. 9). Hydrate formation during the pozzolanic reaction is, therefore, carried out over a long period. Shi and Day [44] have already described the pozzolanic reaction evolution at isothermal temperature with a linear hyperbolic function. This function is recommended by the concrete maturity method [45] up to 28 days, but shows a limitation for longer curing periods. As pozzolanic reaction occurs during a long period, we assume that the exponential function proposed by Hansen et al. [47] will be more suitable for our data. The equation is as follows:

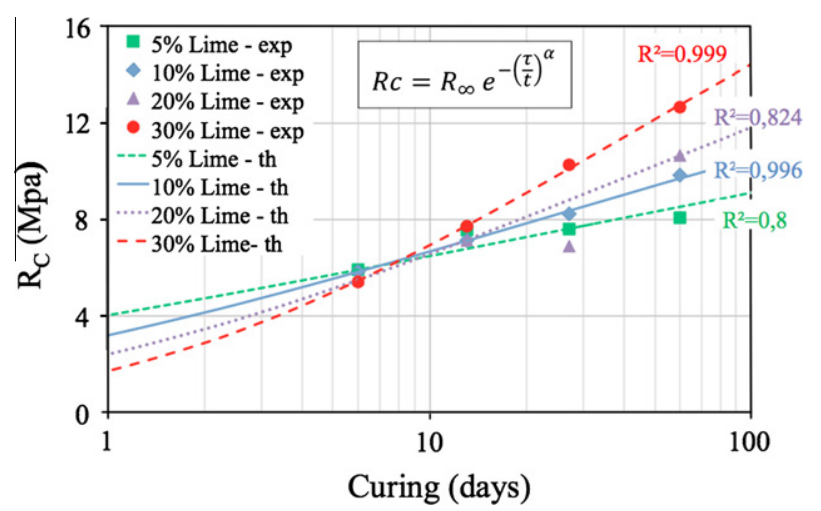

Fig. 9. Pumice-lime binders compressive strength evolution with lime mass content and time.

$R_{c}=R_{\infty} e^{-\left(\frac{\tau}{t}\right)^{\alpha}}$

where $R_{c}$ is the compressive strength after $t$ days of curing; $R_{\infty}$, the compressive strength estimated at $t_{\infty} ; t$, the age of the binder; $\tau$, the time constant; and $\tau=0.37 R_{\infty}, \alpha$ is the shape parameter

The least square method was applied on compressive strength values for 7, 14, 28 and 60 days of curing. For each lime proportion, the best-fitted exponential equation was found. Results show good correlation of experimental data with the fitted analytical model. A comparison between linear hyperbolic and exponential model for the 90/10 pumice-lime binder is done in Fig. 10a. The purpose was to determine how these models are able or not to predict correctly thelong-term strength evolution of pozzolanic binders from experimental values obtained up to 28 days of curing. The model functions were then calculated from the 7,14 and 28 day compressive strength measurements. At 280 days, deviation between experimental results and analytical values is $14.5 \%$ for the exponential model and $34.5 \%$ for the linear hyperbolic one. The exponential model curve also shows a good ability to predict longterm strength growth from short-term measurement.

Regarding the mechanical behaviour of the binder, it is similar to that of a conventional hydraulic binder (see Fig. 10b). Focusing on short-term reactive medium, the $\mathrm{pH}$ test showed that even with use of neutral silico-aluminate sand lime is dissolved first and imposes a pH close of 12.5 [46]. According to Shi and Day [46], a higher $\mathrm{pH}$ increases silico-aluminate dissolution rate. However, this basic medium short-term development would be favourable to $\mathrm{Ca}^{2+}$ capture in the polymeric structure of aggregate surface pectins [30]. This could greatly decrease concrete ability to combine silico-aluminate ions in creating poor calcium ion medium.

\subsubsection{Plant concrete mechanical testing}

Before mechanical testing, control tests performed with phenolphthalein were done. Results highlight that specimen curing at saturated humidity make it possible to avoid $\mathrm{Ca}(\mathrm{OH})_{2}$ carbonation. The pozzolanic reaction was then the only stiffening process to occur. The compression test results obtained on the specimens

Table 4

Chemical composition of hemp hurd, hemp fibres, sunflower stem woody part and sunflower stem pith.

\begin{tabular}{|c|c|c|c|c|c|c|}
\hline & $\begin{array}{l}\text { Cellulose } \\
(\text { cellulose } \alpha)(\%)\end{array}$ & $\begin{array}{l}\text { Hemicelluloses } \\
\text { (cellulose } \beta, \gamma)(\%)\end{array}$ & Lignin (\%) & Pectins (\%) & Ashes (\%) & Waxes and Proteins (\%) \\
\hline Hemp hurd [41] & 48 & 12 & 28 & 6 & 2 & 4 \\
\hline Hemp fibre [41] & 55 & 16 & 4 & 18 & 4 & 3 \\
\hline Hemp fibre [30] & 56.1 & 10.9 & 6 & 20.1 & - & 7.9 \\
\hline Sunflower whole stem [43] & 42.1 & 29.7 & 13.4 & 5.9 & 7.9 & 1 \\
\hline Sunflower whole stem [42] & 38.6 & 22.8 & 16.2 & - & 12.2 & - \\
\hline Sunflower stem without pith [42] & 41.4 & 30 & 18.3 & - & 8.9 & - \\
\hline Sunflower stem pith [40] & 47.4 & 9.4 & 3.5 & 6 & 20.4 & - \\
\hline
\end{tabular}



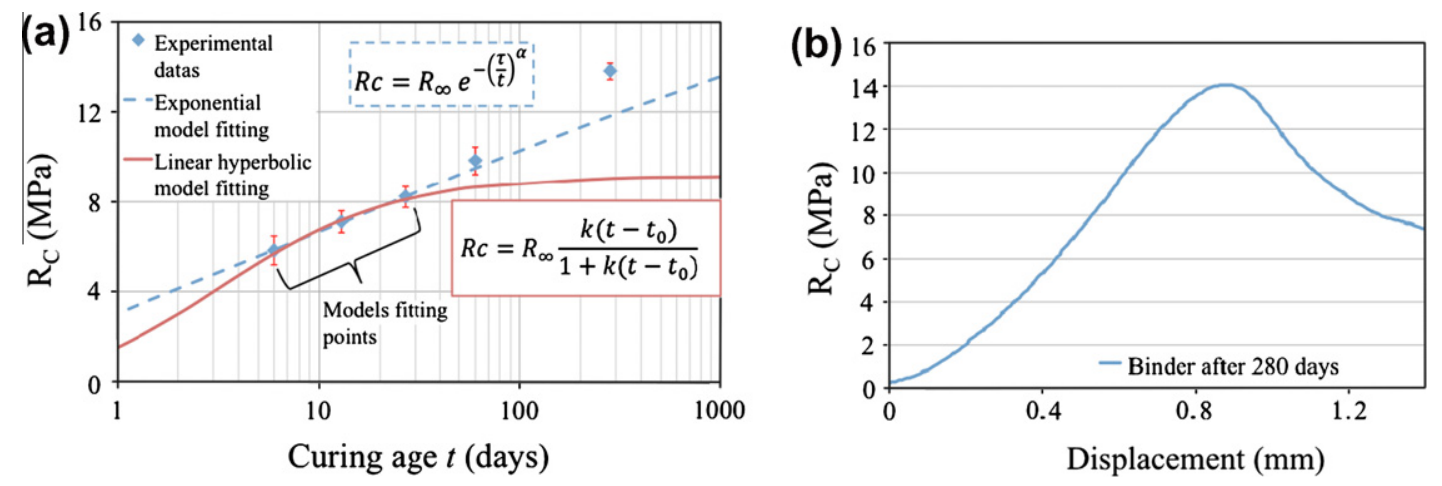

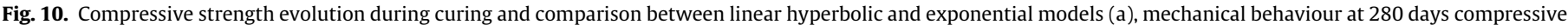
test (b) for the pumice-lime binder B-5 MPa.

Table 5

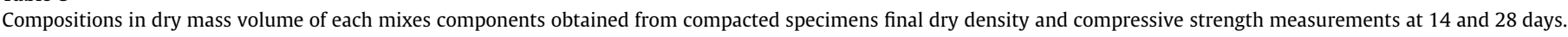

\begin{tabular}{|c|c|c|c|c|c|c|c|}
\hline Mix type & & $\begin{array}{l}\text { Measured concrete dry } \\
\text { density }\left(\mathrm{kg} \mathrm{m}^{-3}\right)\end{array}$ & $\begin{array}{l}\text { Pumice sand } \\
\left(\mathrm{kg} \mathrm{m}^{-3}\right)\end{array}$ & $\begin{array}{l}\text { Lime CL90 } \\
\left(\mathrm{kg} \mathrm{m}^{-3}\right)\end{array}$ & $\begin{array}{l}\text { Vegetable } \\
\left(\mathrm{kg} \mathrm{m}^{-3}\right)\end{array}$ & $\begin{array}{l}\text { Experimental }^{\mathrm{a}} \\
\mathrm{Rc}_{14}(\mathrm{MPa})\end{array}$ & Experimental $^{\mathrm{a}} \mathrm{Rc}_{28}(\mathrm{MPa})$ \\
\hline B-5 MPa & Pumice-lime binder & 1310 & 1179 & 131 & - & 7.11 & 8.21 \\
\hline $\mathrm{H}-2 \mathrm{MPa}$ & Hemp aggregate + binder & 1184 & 1003 & 118 & 63 & 2.14 & 2.77 \\
\hline $\mathrm{H}-5 \mathrm{MPa}$ & & 1266 & 1073 & 126 & 67 & 5.44 & - \\
\hline $\mathrm{S}-2 \mathrm{MPa}$ & Sunflower aggregate + binder & 1084 & 919 & 108 & 57 & 1.63 & 2.52 \\
\hline $\mathrm{S}-5 \mathrm{MPa}$ & & 1204 & 1020 & 120 & 64 & 4.68 & - \\
\hline
\end{tabular}

All compressive strength tests were done on the direction perpendicular to the direction of loading.

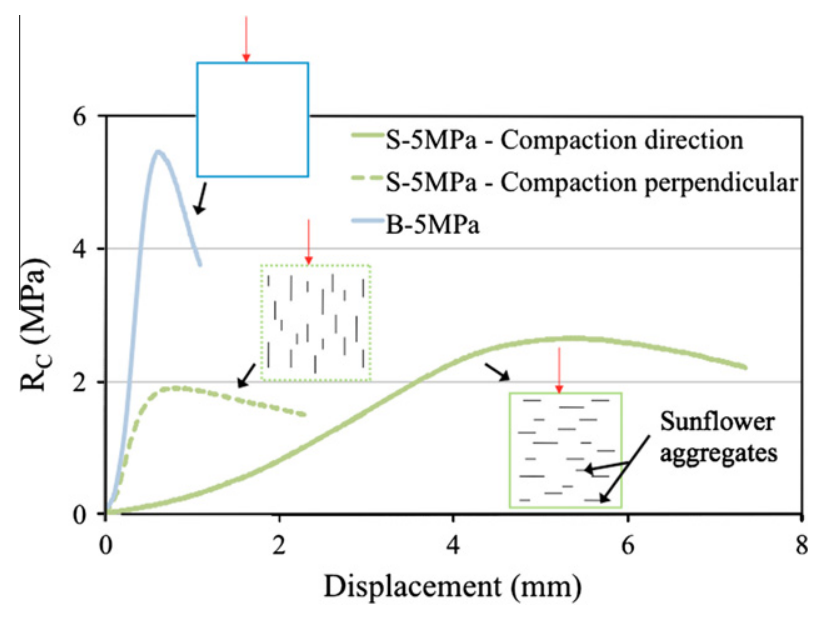

Fig. 11. Plant concrete S-5 MPa mechanical behaviour compared to binder in the compaction and compaction perpendicular directions.

containing plant particles lead to similar results between the sunflower stem aggregate and hemp hurd (see Table 5). Overall, switching from $2 \mathrm{MPa}$ compaction to $5 \mathrm{MPa}$ compaction can double the mechanical strength at 14 days. It is interesting to note that the density variation generated is far from being proportional to the increase, as it goes from 1184 to $1266 \mathrm{~kg} \mathrm{~m}^{-3}(+7.2 \%)$ and from 1084 to $1204 \mathrm{~kg} \mathrm{~m}^{-3}$ (+11.1\%), respectively for aggregates from hemp or sunflower. The study of hemp concrete shaped by compaction has been addressed by Butschi et al. [27] and Cerezo [21]. However, only Nguyen et al. [26] performed experiments using material elements with a density close to $1000 \mathrm{~kg} \mathrm{~m}^{-3}$. All these authors have also observed a significant increase in mechanical strength compared to traditional casting.

Compression curves of elaborated plant concretes present the same appearance as those of the binder (See Fig. 11), especially in the direction perpendicular to compaction. However, behaviour of these materials is more ductile because of plant presence, notably after rupture and when compressing in the direction of loading. Behaviour is nevertheless closer to that of a binder than a plant concrete one $[21,26]$ because of the little amount of plant incorporated. This little amount is, however, sufficient to create a laminated structure when the concrete is cast with a compaction device. Material is then orthotropic and needs to be studied as such. Plant observation shows a similar organisation with wood. This natural composite material is well-known for its longitudinal compressive strength and elastic modulus around ten times higher than in the tangential or radial ones. When the compression test is done in the stratum parallel direction, plant particles are met in the longitudinal direction and results show higher rigidity for the material. On the other hand, rupture happens at less important compressive strength. In the compaction direction, ductility seems to be more important. Two hypotheses can be done. (1) Plant particles are crushed and lead to significant deformation. (2) Matrix particle interface is not perfect and particles are surrounded by holes or powdered binder. When compression is done in the direction of loading, rupture is also less brittle, because material stratums are perpendicular to compression and greatly limit interfacial shearing.

\subsection{Microstructure analysis}

SEM analysis (Fig. 12a) shows pumice grains bigger than $10 \mu \mathrm{m}$, which were not dissolved. It is due to the use of raw sand containing big pumice elements. A mineral matrix composed of several calcium hydrates and resulting from the previously described pozzolanic reaction surrounds them. The punctual EDX analysis results for $\mathrm{H}-5 \mathrm{MPa}$ mix are reported in the $\mathrm{CaO}-\mathrm{Al}_{2} \mathrm{O}_{3}-\mathrm{SiO}_{2}-\mathrm{H}_{2} \mathrm{O}$ ternary diagram (Fig. 12b). They clearly follow a composition line between $\mathrm{Ca}(\mathrm{OH})_{2}$ and pumice sand amorphous phase. Compounds formed in the concrete hang on the same silica/alumina ratio as the reactive amorphous glass of the pumice sand. 

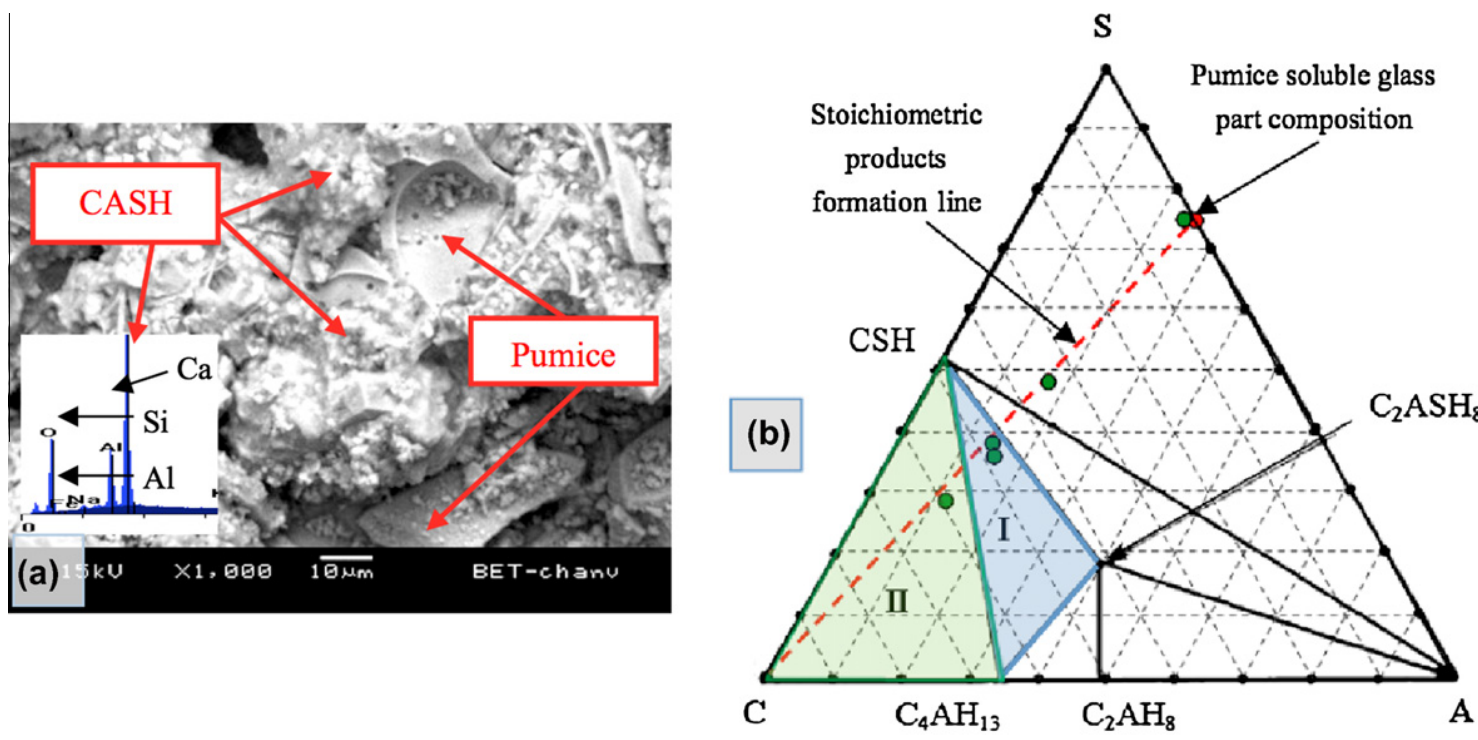

- Pumice sand glass chemical composition [40]

- Pinpoint EDX analysis on H-5MPa mix

Fig. 12. H-5 MPa matrix SEM observation (a) and resulting EDX analysis carried forward in a $\mathrm{CaO}-\mathrm{Al}_{2} \mathrm{O}_{3}-\mathrm{SiO}_{2}-\mathrm{H}_{2} \mathrm{O}$ ternary phase diagram (b).
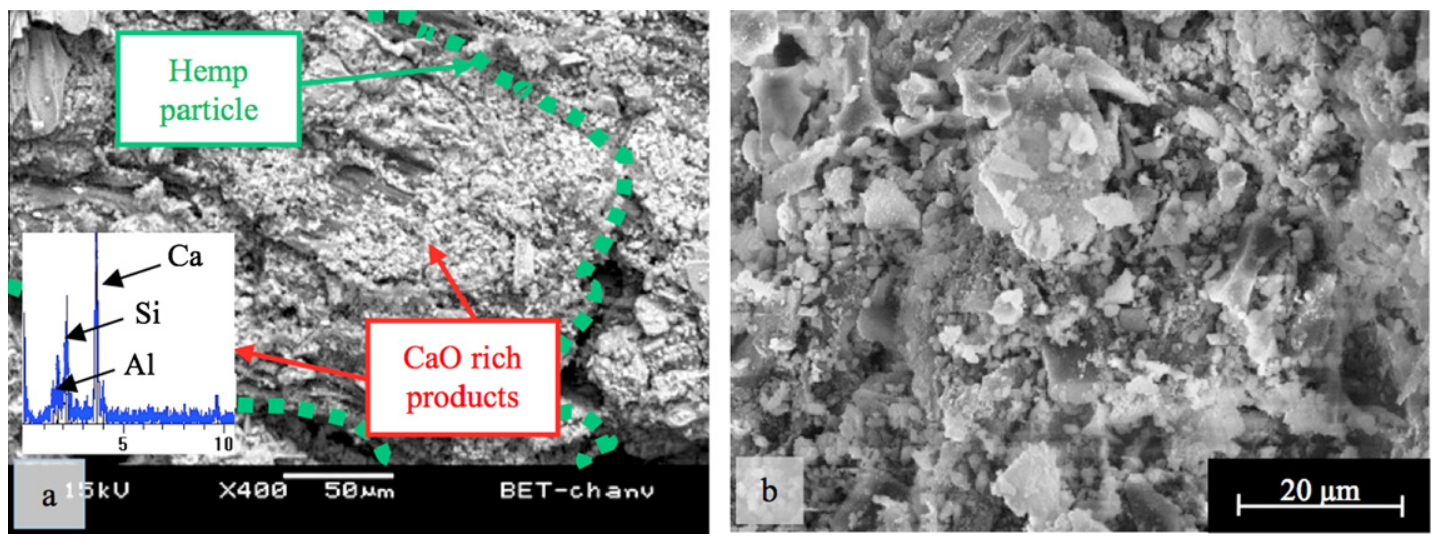

Fig. 13. Hemp hurd particle surface coating (a) and $\mathrm{CaO}$ rich phases (b). SEM observations made on $\mathrm{H}-5 \mathrm{MPa}$ mix.

With a more precise look at the hemp aggregate pulled out from the matrix, some compounds are visible on surface. EDX diffraction spectrum allows one to see that the particle surface is coated with $\mathrm{CaO}$ rich phases (See Fig. 13). Higher magnification makes it possible to distinguish many $\mathrm{Ca}(\mathrm{OH})_{2}$ particles of flat shape and a $\mathrm{CaO}$ rich gel. These results correlate with previous studies made on hemp fibres [30]. Even with lower pectin content, hemp hurd also has the ability to trap $\mathrm{Ca}^{2+}$ in their pectin structure and then to form $\mathrm{CaO}$ rich gel on the aggregate surface.

The best way to visually observe interface between plant aggregates and matrix was optical microscopy. A non-solidified product halo is visible at low magnification around plant particles. However, some compounds are formed on their surface (See Fig. 14a). Khazma et al. [19] also observed what they called a gap zone between flax shave particles and a cement matrix when no treatments are realised on the particles. In their case, interface between lignocellulosic aggregate and matrix is partially composed of a hole in the band with a thickness from 10 to $20 \mu \mathrm{m}$ and non-reacted products. In our case, two hypotheses can be drawn. (1) Plant aggregates are surrounded by non-reacted lime and pumice sand partially removed during the observation of the sample preparation (See Fig. 14b). (2) Plant aggregates are surrounded by holes or gap zones (See Fig. 14c).

\subsection{Mechanical strength prediction analytic model}

For this point, previous research has shown that the compression strength of a cement paste depends on its solid volume. There are a number of formulas published on cement and concrete compression strength predication (Powers, Feret, Bolomey, Abrams) [48]. We consider a compacity model based on Powers' equation to predict the compression strength of plant concrete compared to the binder reference and knowing the compacity of each material.

In a classical structural concrete, the interface between aggregates and binder represents the weakest point of the system. In our case, it is the aggregates, while the binder mostly supplies mechanical performances. The following hypotheses were made. (1) Plant particles are considered in the final material as voids, as the SEM analysis and previous studies [26] show the high porosity 

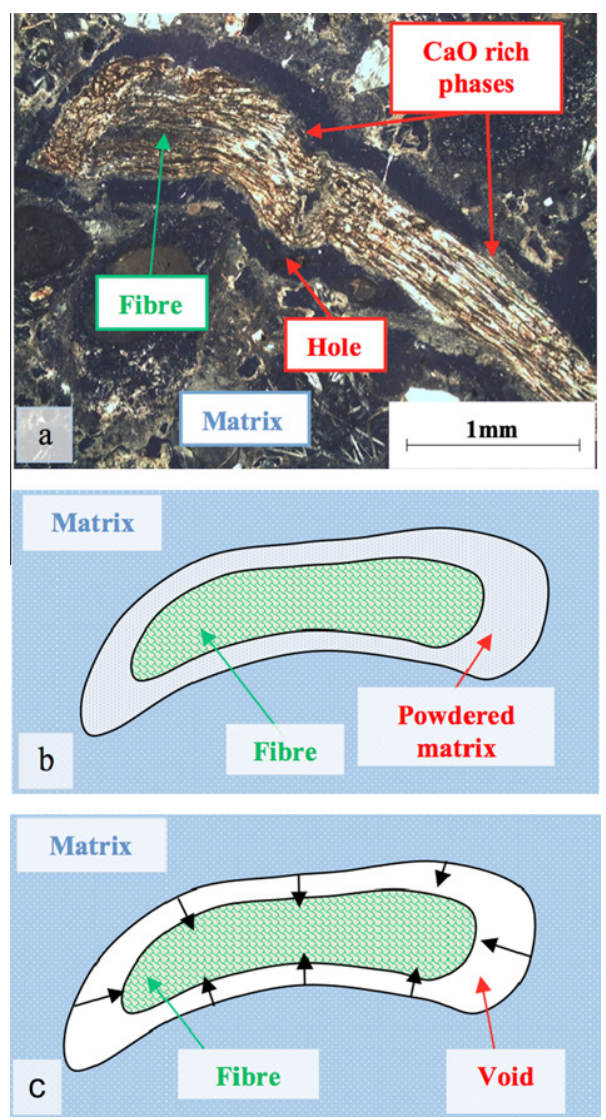

Fig. 14. H-5 MPa mix matrix-plant particle interface observation in optical microscopy (a), hypotheses concerning matrix/fibre interface: particle surrounded by powdered matrix (b), and particle surrounded by void (c).

of plant materials and the lack of adhesion at the plant aggregate/ binder interface. (2) The total volume of water is also considered as void, as the pozzolanic reaction need for water is small compared to that of Portland cement [49]. Product formation volume changes are not taken into account. (3) The aggregates are immersed in the matrix without any contact between them. Our mix proportioning with low plant content satisfies this condition. (4) As the plant particle elasticity is solicited in the compaction direction, we decided to consider the compression strength in the direction perpendicular to loading to avoid this effect. The relation proposed for this application is derived from the classical Feret equation and has been proposed by Powers [48]:

$R_{C}=K_{p}\left(\frac{V_{b}}{V_{b}+V_{w}+V_{v}}\right) \phi_{0}^{3}$

where $R_{C}$ is the compressive strength; $K_{P}$, the Powers' law coefficient; $V_{b}, V_{w}, V_{v}$, the respectively binder, water and void relative volume in the mix; and $\phi_{0}$ is the binder relative solid volume.

In the calculation of the relative solid volume of the binder, matrix is taken in account, whereas the concrete solid aggregates are

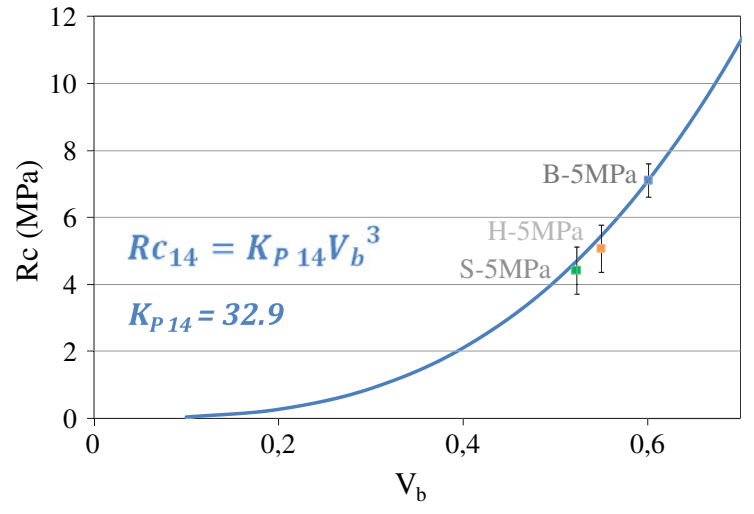

Fig. 15. Binder and elaborated plant concrete compressive strength at 14 days as a function of binder solid volume $V_{b}$. Comparison with Powers law model for binder compressive strength (solid curve).

not. As we consider plant aggregates as voids in our material, concrete is reduce to a simple binder with important porosity. Binder solid volume then follows the simple relation:

$\phi_{0}=\frac{V_{b}}{V_{b}+V_{w}+V_{v}+V_{v e g}}=\frac{V_{b}}{1}=C_{b}$

where $V_{\text {veg }}$ is the plant aggregate relative volume in the mix; $c_{b}$, the compacity of the binder deduced from dry densities measurements of the samples.

Concrete analytical compressive strength is then deduced from the simple relation:

$R_{c}=K_{p} c_{b}^{3}$

To predict the strength of our plant concrete made with the pumice-lime binder, we first calculate the constant $K_{P}$ between the binder density and the binder compression strength for a given curing period. This constant represents the maximum compressive strength the binder would supply without any porosity at this age. Then the concrete strength is deduced after the calculation of the compacity of each mix (see Table 6). Fig. 15 shows that the resistance measured at 14 days agrees well with the proposed formula only for plant concretes compacted at $5 \mathrm{MPa}$. In this case, measurements relate with good accuracy the fact that the plants can be considered as voids and affect negatively the strength of the initial matrix. For the $2 \mathrm{MPa}$ compacted concretes, the same porosity level leads to a lower compressive strength and does not follow Powers' relation. As the casting process of these samples is different from that of the binder, a comparison cannot be made. These results must be taken with caution as they are very sensitive to experimental conditions, particularly the direction of the compression, the curing conditions and the plant quantities. As the interface between plant particles and the matrix is not perfect, it is important to better understand and control this zone to be able to predict relatively accurately concrete performances with higher plant proportioning.

Table 6

Powers's law parameters calculation and comparison between experimental and theoretical values at 14 days.

\begin{tabular}{|c|c|c|c|c|c|}
\hline Mix & $\Phi_{0}=c_{b}$ & $\begin{array}{l}\text { Experimental }^{\mathrm{a}} \\
\mathrm{Rc}_{14}(\mathrm{MPa})\end{array}$ & $\mathrm{K}_{\mathrm{P} 14}(\mathrm{MPa})$ & $\begin{array}{l}\text { Theoritical } \mathrm{Rc}_{14} \\
\text { POWERS }(\mathrm{MPa})\end{array}$ & $\begin{array}{l}\text { Experimental deviation } \\
\text { from model }(\%)\end{array}$ \\
\hline B-5 MPa & 0.6 & 7.11 & 32.9 & 7.11 & - \\
\hline $\mathrm{H}-5 \mathrm{MPa}$ & 0.549 & 5.08 & 32.9 & 5.44 & 7 \\
\hline S-5 MPa & 0.522 & 4.43 & 32.9 & 4.68 & 6 \\
\hline
\end{tabular}

a All compressive strength tests were done on the direction perpendicular to the direction of loading. 


\section{Conclusion}

Two aggregates designed from local plants were analysed for this work. Multi-scale morphology observations of sunflower stem aggregates, as well as water absorption ability, reveal interesting similarities between sunflower and hemp stems. This is also the case when looking at literature on sunflower and hemp stem chemical analysis (cf. Table 4). As the stem is a sunflower by-product and is available in high quantities, it is therefore a possible alternative to hemp hurd for plant concrete use.

With the purpose to use local raw materials as much as possible, a binder made of pumice sand and calcic lime CL90 was designed. Mechanical behaviour under compression confirms the interest of lime-pozzolan binders for future development. Even with raw sand, a binder made with a pumice/lime ratio of $90 \% /$ $10 \%$ in weight led to a compressive strength greater than $8 \mathrm{MPa}$ after 28 days. Plant concrete is currently elaborated with limebased binders showing similar values [21]. However, pumice sand contains a part of crystalline silica that could limit its use to precast products.

Study was then angled toward industrial product design with the use of the compaction device. Casting by compaction shows the high capability of the plant aggregate to be reorganised in layers and then to form a concrete with orthotropic mechanical behaviour. It is also an interesting way to increase greatly compressive strength without increasing density of the material in the same proportions because of resulting orthotropic properties. The shape of the plant particle is then a very important characteristic to be determined because long and flat objects will have the ability to be reorganised in layers during compaction. Image analysis represents a simple tool to provide this information.

The mechanical model based on Powers' equation underlines the fact that plant aggregates could be considered as voids dispersed in the matrix as they play a minor role in the composite compressive strength. As SEM and optic microscope observations underline interfacial problems between matrix and plant aggregates, this relation can be only used for low plant particle contents. The addition of more plant in proportion will certainly increase these problems because of gap zone lapping. It could then create binder setting and hardening problems and modify greatly its properties. In light of these questions, future studies will focus on plant adapted treatments, as well as binder design in the goal to improve the binder/plant interface.

\section{References}

[1] Brandt AM. Fibre reinforced cement-based (FRC) composites after over 40 years of development in building and civil engineering. Compos Struct 2008;86(1-3):3-9.

[2] Coutts RS. A review of Australian research into natural fibre cement composites. Cem Concr Compos 2005;27(5):518-26.

[3] Tonoli G, Savastano Jr H, Fuente E, Negroc C, Blancoc A, Rocco Lahr FA. Eucalyptus pulp fibres as alternative reinforcement to engineered cementbased composites. Ind Crop Prod 2010;31(2):225-32.

[4] Li Z, Wang X, Wang L. Properties of hemp fibre reinforced concrete composites. Compos Part A: Appl Sci Manuf 2006;37(3):497-505.

[5] Li Y, Mai Y, Ye L. Sisal fibre and its composites: a review of recent developments. Compos Sci Technol 2000;60(11):2037-55

[6] Ghavami K, Toledo Filho RD, Barbosa NP. Behaviour of composite soil reinforced with natural fibres. Cem Concr Compos 1999;21(1):39-48.

[7] Toledo Filho RD, Ghavami K, England GL, Scrivener K. Development of plant fibre-mortar composites of improved durability. Cem Concr Compos 2003;25(2):185-96.

[8] Kriker A, Debicki G, Bali A, Khenfer M, Chabannet M. Mechanical properties of date palm fibres and concrete reinforced with date palm fibres in hot-dry climate. Cem Concr Compos 2005;27(5):554-64.

[9] Sudin R, Swamy N. Bamboo and wood fibre cement composites for sustainable infrastructure regeneration. J Mater Sci 2006;41(21):6917-24.

[10] Aggarwal LK. Bagasse-reinforced cement composites. Cem Concr Compos 1995;17(2):107-12.
[11] Bilba K, Arsene M. Silane treatment of bagasse fiber for reinforcement of cementitious composites. Compos Part A: Appl Sci Manuf 2008;39(9): 1488-95.

[12] Savastano H, Warden PG, Coutts RSP. Brazilian waste fibres as reinforcement for cement-based composites. Cem Concr Compos 2000;22(5):379-84.

[13] Agopyan V, Savastano J, John V, Cincotto M. Developments on plant fibrecement based materials in Sao Paulo, Brazil: an overview. Cem Concr Compos 2005;27(5):527-36.

[14] Becchio C, Corgnati SP, Kindinis A, Pagliolico S. Improving environmental sustainability of concrete products: Investigation on MWC thermal and mechanical properties. Energy Build 2009;41(11):1127-34.

[15] Turgut P, Murat Algin H. Limestone dust and wood sawdust as brick material. Build Environ 2007;42(9):3399-403.

[16] Semple KE, Cunningham RB, Evans PD. The suitability of five Western Australian mallee eucalypt species for wood-cement composites. Ind Crop Prod 2002;16(2):89-100.

[17] Karus M, Vogt D. European hemp industry: cultivation, processing and product lines. Euphytica 2004;140(1):7-12.

[18] Aamr-Daya E, Langlet T, Benazzouk A, Queneudec M. Feasibility study of lightweight cement composite containing flax by-product particles: physicomechanical properties. Cem Concr Compos 2008;30(10):957-63.

[19] Khazma M, El Hajj N, Goullieux A, Dheilly RM, Queneudec M. Influence of sucrose addition on the performance of a lignocellulosic composite with a cementious matrix. Compos Part A: Appl Sci Manuf 2008;39(12):1901-8.

[20] Arnaud L. Mechanical and thermal properties of hemp mortars and wools: experimental and theoretical approaches. Bioresource Hemp 2000 \& other fibre crops. Wolfsburg; 2000.

[21] Cerezo V. Propriétés mécaniques, thermiques et acoustiques d'un matériau à base de particules végétales - mechanical, thermal and acoustical properties of a plant particle based material. French document, PhD thesis. INSA Lyon; 2005.

[22] Evrard A. Sorption behaviour of Lime-Hemp concrete and its relation to indoor comfort and energy demand. In: 23rd Conference on passive and low energy architecture. Geneva; 2006.

[23] De Bruijn PB, Jeppsson K, Sandin K, Nilsson C. Mechanical properties of limehemp concrete containing shives and fibres. Biosyst Eng 2009;103(4):474-9.

[24] Elfordy S, Lucas F, Tancret F, Scudeller Y, Goudet L. Mechanical and thermal properties of lime and hemp concrete ("hempcrete") manufactured by a projection process. Constr Build Mater 2008;22(10):2116-23.

[25] Nguyen T, Picandet V, Carre P, Lecompte T, Amziane S, Baley C. Effect of compaction on mechanical and thermal properties of hemp concrete. Eur J Environ Civil Eng 2010;14(5):545-60.

[26] Nguyen T, Picandet V, Amziane S, Baley C. Influence of compactness and hemp hurd characteristics on the mechanical properties of lime and hemp concrete. Eur J Environ Civil Eng 2009;13(9):1039-50.

[27] Butschi PY, Deschenaux C, Miao B, Srivastava N. Characterization of masonry consisting of bonded hemp elements. Can J Civil Eng 2004;31(3):526-9.

[28] Peschard A, Govin A, Pourchez J, et al. Effect of polysaccharides on the hydration of cement suspension. J Eur Ceram Soc 2006;26(8):1439-45.

[29] Laskowski J, Liu Q O'Connor C. Current understanding of the mechanism of polysaccharide adsorption at the mineral/aqueous solution interface. International Journal of Mineral Processing 2007;84(1-4):59-68.

[30] Sedan D, Pagnoux C, Chotard T, et al. Effect of calcium rich and alkaline solutions on the chemical behaviour of hemp fibres. J Mater Sci 2007;42(22):9336-42.

[31] Dronnet VM, Renard CMGC, Axelos MAV, Thibault J-. Binding of divalent metal cations by sugar-beet pulp. Carbohyd Polym 1997;34(1-2):73-82.

[32] Ralet M, Dronnet V, Buchholt HC, Thibault J. Enzymatically and chemically deesterified lime pectins: characterisation, polyelectrolyte behaviour and calcium binding properties. Carbohyd Res 2001;336(2):117-25.

[33] Topçu IB. Semi lightweight concretes produced by volcanic slags. Cem Concr Res 1997;27(1):15-21.

[34] Sahin S, Orung I, Okuroglu M, Karadutlu Y. Properties of prefabricated building materials produced from ground pumice aggregate and binders. Constr Build Mater 2008;22(5):989-92

[35] Ghrici M, Kenai S, Said-Mansour M. Mechanical properties and durability of mortar and concrete containing natural pozzolana and limestone blended cements. Cem Concr Compos 2007;29(7):542-9.

[36] Savastano H, Warden PG, Coutts RSP. Ground iron blast furnace slag as a matrix for cellulose-cement materials. Cem Concr Compos 2001;23(45):389-97.

[37] Pichon $\mathrm{H}$. Le système "Pouzzolanes naturelles - Chaux - Eau» à 38 et $100^{\circ} \mathrm{C}-$ " Natural Pozzolan - Lime - Water» system at $38^{\circ} \mathrm{C}$ and $100{ }^{\circ} \mathrm{C}$. French document, PhD thesis. University of Grenoble I; 1992.

[38] Pavía S, Treacy E. A comparative study of the durability and behaviour of fat lime and feebly-hydraulic lime mortars. Mater Struct 2006;39(3):391-8.

[39] Nazar AM, Silva FA, Ammann JJ. Image processing for particle characterization. Materials Characterization 1999;36(4-5):165-73.

[40] Yin Z, Pan Z, Wang C, Dong Y, Ou Y. Composition, structure and mechanical properties of several natural cellular materials. Chinese Sci Bull 2007;52(21):2903-8.

[41] Garcia-Jaldon C, Dupeyre D, Vignon MR. Fibres from semi-retted hemp bundles by steam explosion treatment. Biomass Bioenergy 1998;14(3):251-60.

[42] Khristova P, Yossifov N, Gabir S. Particle board from sunflower stalks: preliminary trials. Bioresource Technol 1996;58(3):319-21.

[43] Jimenez L, Lopez F. Characterization of paper sheets from agricutural residues. Wood Sci Technol 1993;27(6):468-74. 
[44] Shi C, Day RL. Comparison of different methods for enhancing reactivity of Pozzolans. Cem Concr Res 2001;31(5):813-8.

[45] Carino NJ, Lew HS. The maturity method: from theory to application. Structures Congress \& Exposition. American Society of Civil Engineers, Reston, Virginia; 2001.

[46] Shi C, Day RL. Pozzolanic reaction in the presence of chemical activators. Part II: Reaction products and mechanism. Cem Concr Res 2000;30(4):607-13.
[47] Freiesleben Hansen P, Pedersen J. Curing of concrete structures. CEB Information Bulletin; 1985.

[48] Larrard FD. Concrete mixture proportioning: a scientific approach. Spon Press; 1999.

[49] Dron R. L'activité pouzzolanique. The pozzolanic activity. French document Bulletin de liaison Laboratoire des Ponts et Chaussées; 1978. p. 66-9. 